\title{
Clinicopathological study of Refsum's disease with particular reference to fatal complications
}

\author{
I N G R I D V.A L L E N, M. S W A L L OW, N. C. NEV I N, A N D \\ D. M C C O R M I C K
}

From the Institute of Neurological Sciences, The Royal Victoria Hospital, and The Queen's University of Belfast, Belfast

SUM MARY The clinical and pathological findings in two brothers with biochemically diagnosed Refsum's disease are given. The pathology, in general, was that already described in this condition. An unusual complication in one case was the development of renal failure. Death was caused in the other by heart failure.

Nevin et al. (1967) reported the clinical findings in a family with Refsum's disease in which a sister and two brothers were affected: postmortem findings were given in the case of the sister. The parents and the two affected brothers have subsequently been studied biochemically by Herndon $e t$ al. (1969). The brothers have since died, and this paper describes the clinical progress and pathological abnormalities in these two patients.

\section{Case reports}

CASE 1

The patient (JS, case 3, Nevin et al., 1967) was admitted to hospital in May 1970 for review at the age of 49 years. During the previous three years there had been a gradual deterioration in his general condition. He had become progressively unsteady on his feet and for five months had been unable to walk without support: in January 1970 he developed numbness in the fingers. In September 1968 he had an attack of acute glaucoma in his right eye which was treated by a peripheral iridectomy (Mr P. Gormley).

On examination he was blind and completely deaf, and the only way in which his family could establish contact with him was by writing on the palm of his hand. Unfortunately, with increasing numbness, even this method had become unreliable, and neurological assessment was extremely difficult. However, it was observed that he had

Address for reprint requests: Dr Ingrid V. Allen, Department of Pathology, The Royal Victoria Hospital, Belfast BT12, Northern Ireland.

Accepted 24 October 1977 nystagmus on looking to the left and right. In the right eye there was a peripheral iridectomy, a mature cataract with loss of the anterior chamber, and bullous corneal dystrophy. Muscular power and tone in the arms and legs were normal, but all the tendon reflexes were absent. Plantar responses were flexor. His gait was unsteady with severe truncal ataxia. There was impairment to pinprick in a glove and stocking distribution: vibration sense and joint position sense were absent in the legs. The cardiovascular system was normal; pulse rate was 80 per minute with occasional ectopic beats, and blood pressure was $130 / 80 \mathrm{mmHg}$.

Nerve conduction studies confirmed the presence of a severe peripheral neuropathy. Radiographs of the feet showed short fourth metatarsal bones. The blood urea level was raised: repeated examinations showed values between 22.8 and $27.0 \mathrm{mmol} / 1$. Serum creatinine was $300 \mu \mathrm{mol} / 1$, creatinine clearance $22 \mathrm{ml}$ per minute, total urine volume $2000 \mathrm{ml}$, and total urine protein $1.07 \mathrm{~g} / 24$ hours. Serum calcium was low $(1.93 \mathrm{mmol} / \mathrm{l})$. A drip infusion pyelogram with tomography showed poor function in both kidneys. There was bilateral renal atrophy with replacement of the renal sinus with fibrolipomatous tissue (Dr E. L. McIlrath). The patient was seen by Dr Mary G. McGeown who considered that the diagnosis lay between chronic pyelonephritis and an infiltrative nephropathy. The distinction between these two conditions could only be made by open renal biopsy which was not thought to be justified.

No specific treatment for the renal failure was indicated other than calciferol (50000 units daily) to maintain the level of serum calcium. The patient 
was given a low phytanic acid diet, and discharged from hospital. However, three days later he had to be readmitted with acute retention of urine. Blood urea was $14.1 \mathrm{mmol} / 1$ and serum potassium 5.0 $\mathrm{mmol} / \mathrm{l}$. One litre of urine was removed by catheterisation and subsequently he developed incontinence. On rectal examination, the prostate was not enlarged. The cardiovascular system was normal (BP 140/85 $\mathrm{mmHg}$ ). Six days later he became restless with evidence of bronchopneumonia, and he died the next day.

\section{CASE 2}

This 40 year old man (ES, case 1, Nevin et al., 1967) was reviewed in August 1969 at Claremont Street Hospital for Nervous Diseases. Over the previous five years he had noticed increasing weakness and tiredness in his legs after walking for 15 to 20 minutes. During the previous four to five months he had developed "a spongelike" feeling in the soles of his feet whenever he walked, and occasionally he had a transitory sensation of an "electric current" in his feet.

In April 1970, the patient complained of numbness and tingling in the hands, so that he could no longer read Braille. He was given a diet low in phytanic acid but five months later was readmitted to hospital because of general deterioration in his condition. He now complained of "pins and needles" in the hands and legs, and of increasing difficulty in walking. For the past year his hearing had also deteriorated.

On examination he showed mild weakness of the proximal muscles and marked weakness of the distal muscles of the feet. There was total areflexia, and the plantar responses were absent. Touch sensation in the peripheral parts of the limbs was diminished, and joint position sense was absent in the great toes. Vibration sense was absent below the sternum. His gait was widebased and ataxic. Ophthalmic examination showed marked bilateral miosis, and the pupils dilated poorly. There was a small posterior polar lens opacity in each eye. His central visual acuity was reduced to $6 / 18$. There was marked constriction of the peripheral visual fields amounting to tunnel vision. The fundi showed narrowing and attenuation of the retinal vessels and optic atrophy. $\mathrm{He}$ also had moderate bilateral deafness. $\mathrm{He}$ was discharged from hospital but readmitted one month later complaining of shortness of breath after a "cold".

On examination chest expansion was poor with diminished air entry and coarse crepitations at the bases. There was no evidence of heart failure; BP was $120 / 85 \mathrm{mmHg}$, and pulse 84 per minute.
Chest radiography showed a slight increase in the diameter of the heart shadow; lung fields were normal. An electrocardiogram (ECG) showed evidence of left ventricular enlargement with ST depression in leads 1, and V4 to V6. Haemoglobin was $16.5 \mathrm{gm} / \mathrm{l}$, white cell count 5400 per $\mathrm{mm}^{3}$. Total serum protein concentration was $710 \mathrm{gm} / 1$, and blood urea $8.3 \mathrm{mmol} / \mathrm{l}$.

On 6 October 1970, the patient became restless and complained of tightness and pain in his chest. A further ECG showed no evidence of a myocardial infarct. The pulse rate was 100 per minute and irregular, and blood pressure was $80 / 60$ mmHg: he died suddenly the next day.

\section{Pathology}

\section{MATERIAL AND METHODS}

Postmortem examination was carried out on case 1 (JS) within a few hours of death, and on case 2 (ES) approximately eight hours after death. Tissue blocks were embedded in paraffin or low viscosity nitrocellulose, and frozen sections were also cut. Sections were stained using the following methods: haematoxylin and eosin (H \& E), periodic acidSchiff (PAS) with and without diastase digestion, Southgate's mucicarmine, alcian green, Scharlach R, Nile blue sulphate, Holczinger's stain for free fatty acids, Spielmeyer, Woelcke, Glees Marsland, Mallory's phosphotungstic acid haematoxylin (PTAH).

\section{RESULTS}

The imediate cause of death in both patients was bronchopneumonia.

Cardiovascular system The heart weighed $450 \mathrm{~g}$ in case 1, and $425 \mathrm{~g}$ in case 2: in both there was slight hypertrophy of the left ventricle but there was no other macroscopic lesion. The coronary arteries were atheromatous but patent. Histologically there was slight focal myocardial fibrosis: some of the myocardial fibres were hypertrophied and contained large bizarre-shaped nuclei, and in some fibres clear cytoplasmic vacuoles could be seen (Fig. 1). Frozen sections stained for neutral fat showed fine deposition of fatty droplets around nuclei. In both cases the aorta was slightly atheromatous and there was cystic medial degeneration. Alimentary system There was no abnormality of the oesophagus, stomach, or intestine, and, in particular, the ganglion cells and nerve fibres were normal. In both patients the liver weighed $1600 \mathrm{~g}$; it did not look fatty but histologically the epithelium was vacuolated, and there was extensive deposition of neutral fat (Fig. 2). The gall bladder and pancreas were normal. 


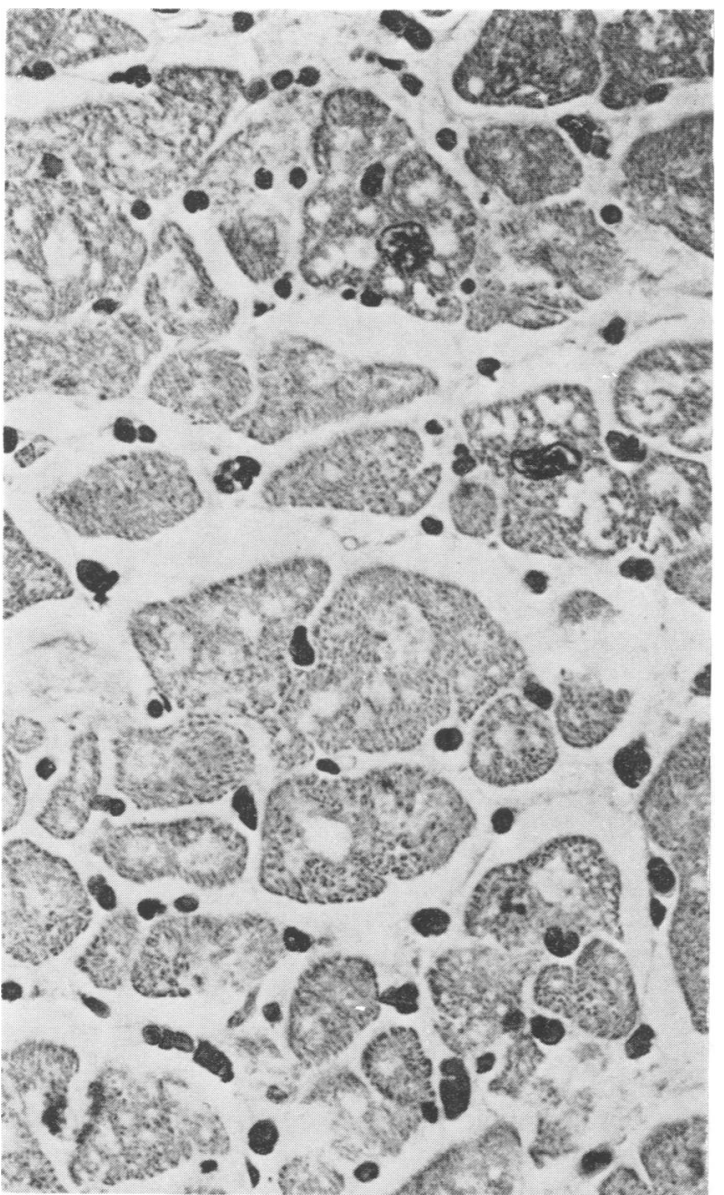

Fig. 1 Heart muscle showing vacuolation of fibre cytoplasm $H \& E \times 400$.

Reticuloendothelial system The spleen $(250 \mathrm{~g}$ in case 1 , and $220 \mathrm{~g}$ in case 2). was normal: hilar lymph nodes showed reactive changes but other lymph nodes were not enlarged, and the bone marrow was normal.

Endocrine glands Pituitary, adrenal, and parathyroid glands were normal; in the thyroid in both cases there was slight variation in acinar size and colloid content but there was no fibrosis or lymphocytic infiltration. The testes were not atrophied on naked eye examination but were not examined histologically.

Urinary system Each kidney in case 1 weighed $200 \mathrm{~g}$ and measured $120 \times 60 \mathrm{~mm}$. The surface was finely scarred, and there was slight atrophy of the renal tissue: on section, marked lipid deposition was seen (Fig. 3). The renal arteries were not atheromatous and were patent. Histologically, many of the glom- eruli were of normal cellularity but some were hyalinised and others showed periglomerular fibrosis with associated lymphocytic infiltration. Many of the tubules were dilated and contained casts. The tubular epithelium was vacuolated, and in frozen sections neutral fat could be demonstrated (Fig. 4). The kidneys in case 2 weighed $180 \mathrm{~g}$ each and measured $115 \times 60 \mathrm{~mm}$. They were not scarred but showed some fatty infiltration in tubular epithelium. In case 1 the prostate was nodular and the bladder showed cystitis cystica. There was no lesion of the bladder or prostate in case 2.

Skeletal system The vertebral bone was of normal consistency: metatarsal bone was not examined. Central nervous system The brain weighed $1400 \mathrm{~g}$ in case 1 , and $1500 \mathrm{~g}$ in case 2 . In both there was slight atheroma of the cerebral arteries but

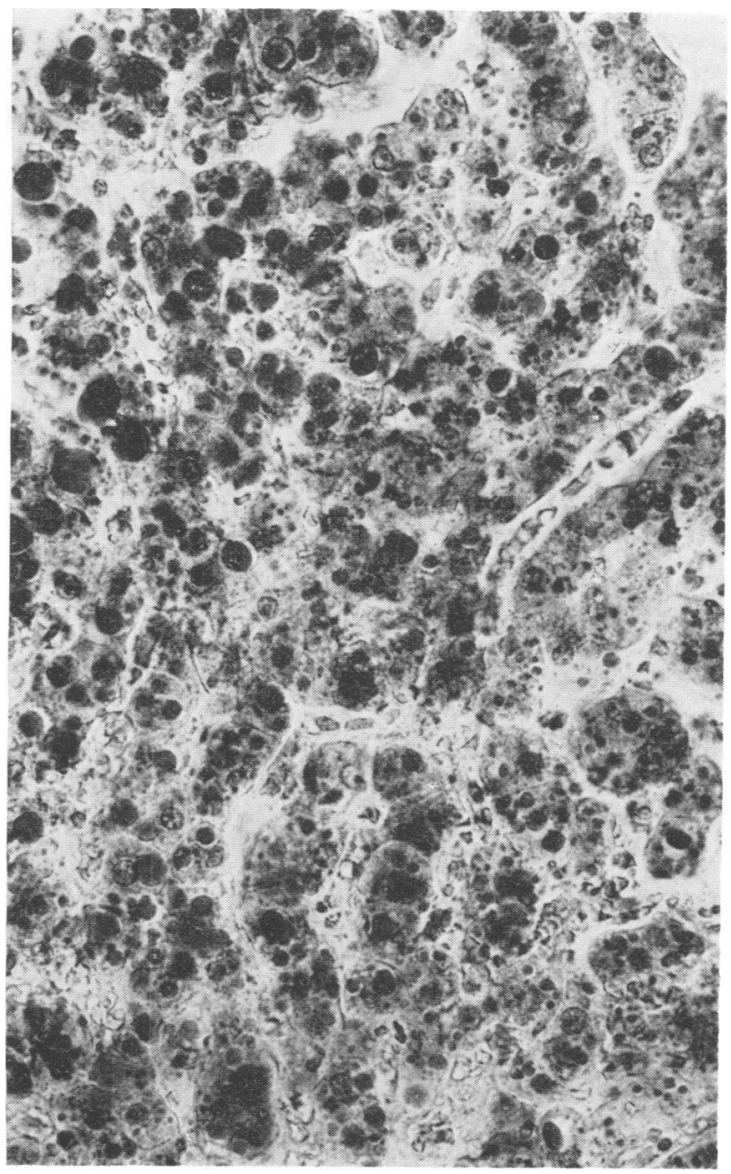

Fig. 2 Liver Fatty droplets are stained in the cell cytoplasm. Frozen section, Scharlach $R \times 250$. 


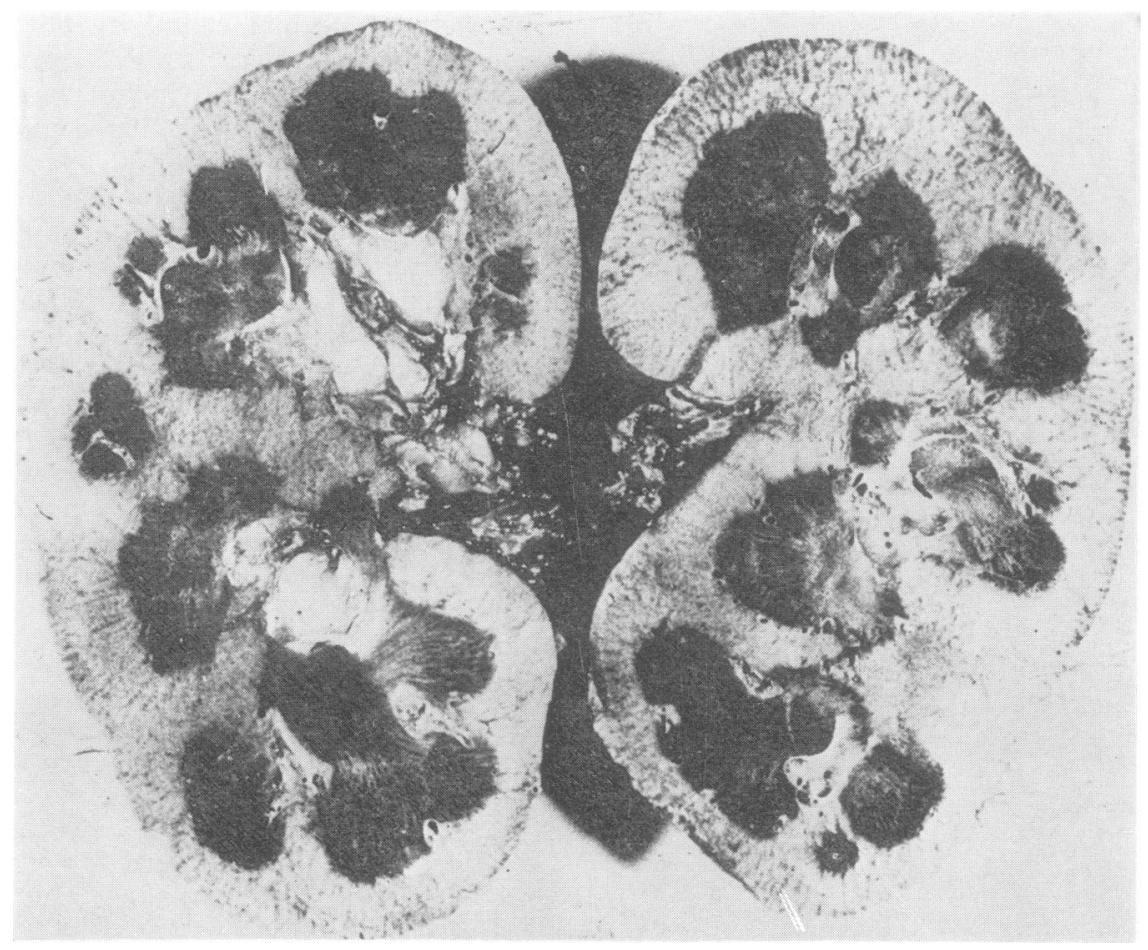

Fig. 3 Kidneys Deposition of fat is seen in cortex and medulla.

no other macroscopic abnormality. In sections from the frontal, parietal, temporal, and occipital cortex the meninges were not thickened and did not contain lipophages. Neutral fat could not be demonstrated in the ependyma but fat was present in the choroid plexus. In the cerebral cortex there was no apparent neuronal loss or increase in neuronal lipid. The basal ganglia did not show cell loss or gliosis but free neutral fat was widely dispersed in the globus pallidus (Fig. 5), and in surrounding white matter small collections of lipophages were seen around blood vessels. In the deep white matter myelin and axis cylinders stained normally. There was, however, a slight generalised increase in numbers of oligodendrocytes, and some of these cells were distorted and had a clear cytoplasm and eccentric nucleus: the latter had the staining reactions of mucocytes as described by Smith (1949) (Fig. 6).

There was no abnormality of neurones or of myelin in the midbrain or pons. Myelin was generally well preserved in the medulla although the funiculus gracilis and funiculus cuneatus were pale. The cerebellar cortex was well preserved, and there was no abnormality of the Purkinje cells; the cerebellar white matter was well myelinated but there was a slight diffuse increase in oligodendrocytes, and mucocytes were again present. The dentate nuclei showed slight gliosis. The optic and juxtacerebral part of the auditory nerves showed loss of myelinated fibres with gliosis, and numerous corpora amylacea were present. The olfactory bulbs and nerves were examined in case 2 ; there was no proliferation of sheath cells. Sections from cervical, thoracic, lumbar, and sacral cord were studied: the grey matter was normal, but there was pallor of myelin staining in the posterior columns (Fig. 7). The ventral and dorsal roots were not thickened but showed poor myelin staining and increased numbers of Schwann cells.

Peripheral nervous system The dorsal root ganglia did not show neuronal loss but there was proliferation of sheath cells. The major peripheral nerve trunks were thickened, and histologically all sections showed a similar picture. The nerve bundles were enlarged and were outlined by a thickened perineurium. Within nerve bundles there was marked Schwann cell proliferation with "onion bulb" formation (Fig. 8), and axis cylinders were widely separated by a clear matrix which stained weakly with PAS and did not stain for fat. There was extensive loss of myelin sheaths though neutral 


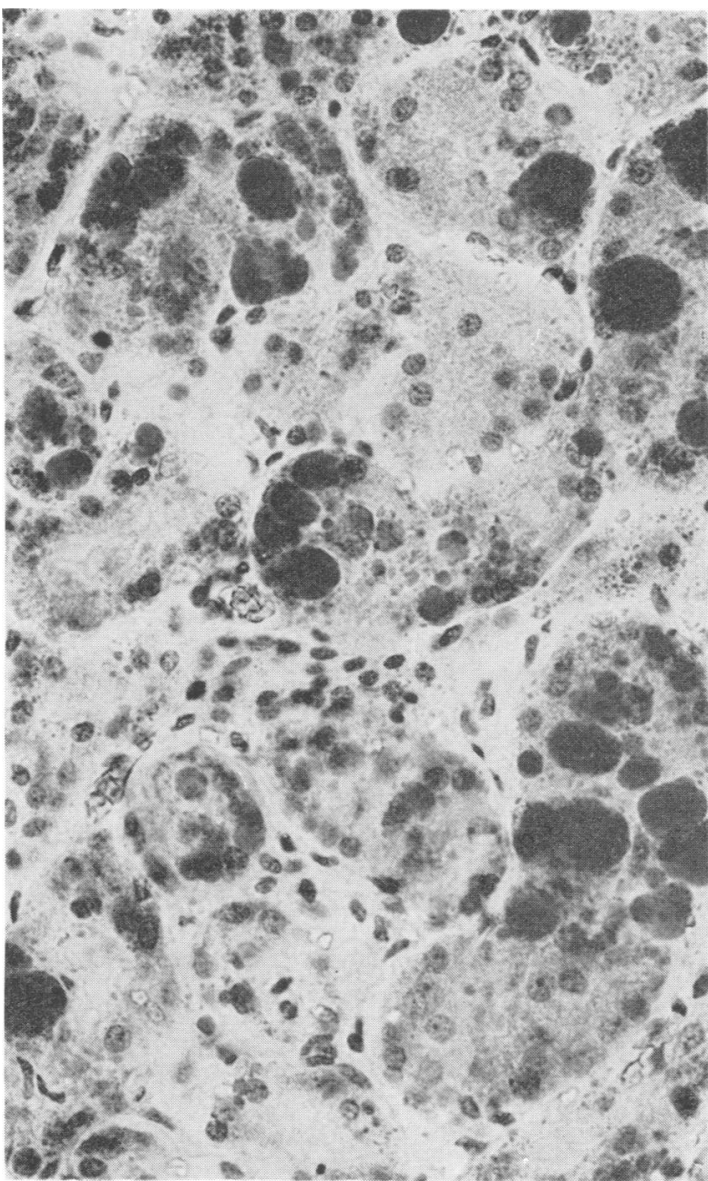

Fig. 4 Renal tubular epithelium stained for fat.

Frozen section, Scharlach $R \times 250$.

fat was not present. The vagi were hypercellular and showed "onion bulb" formation.

Striated muscle Some sections of muscle were normal but in others there was mild neurogenic atrophy: in a few sections enlarged hypercellular muscle spindles were seen.

Eyes The eyes were examined in case 1. They showed the changes of retinitis pigmentosa with loss of rods and cones, and migration of pigment into the non-pigmented areas. PAS positive material was not seen.

Ears The ears were examined in case 2. There was no abnormality in the middle ear, the bony labyrinth was normally formed; the membranous labyrinth was inadequately fixed for histology; PAS positive material was not present. Further pathological studies of the eye and ear are in progress and will be reported at a future date.

\section{Neurochemistry}

MATERIAL AND METHODS

The tissues used for biochemical analyses were obtained at necropsy and stored in $10 \%$ buffered formaldehyde for four years. The control specimens had been in formaldehyde for the same period of time and were from patients of similar ages. The tissue samples were extracted with 35 times their own volume of chloroform: methanol $(2: 1)$ by homogenisation in a teflon/glass tissue grinder. The extract was filtered to remove precipitated protein, and the filtrate was partitioned according to Folch et al. (1957). The lower phase was taken to dryness in a rotary evaporator, and the resultant residue was dissolved in chloroform before chromatographic analysis. Thin layer chromatography was performed on silica gel $G$

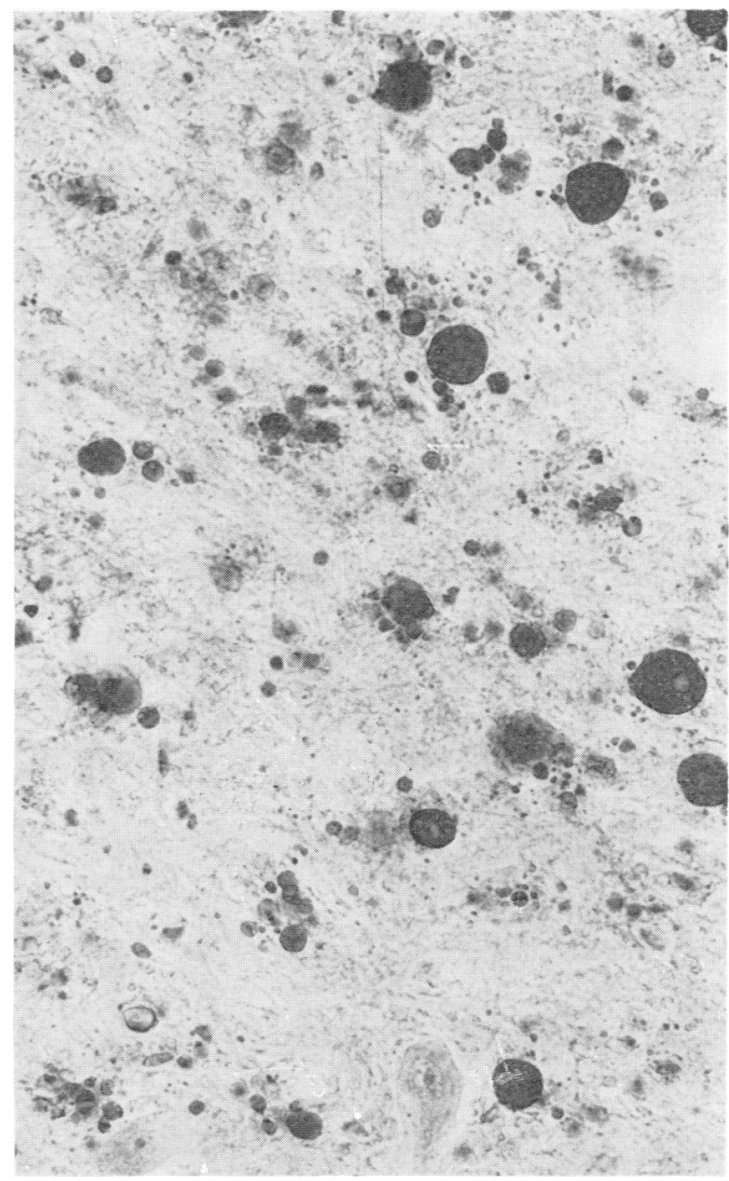

Fig. 5 Fat deposits in globus pallidus. Frozen section, Scharlach $R \times 250$. 


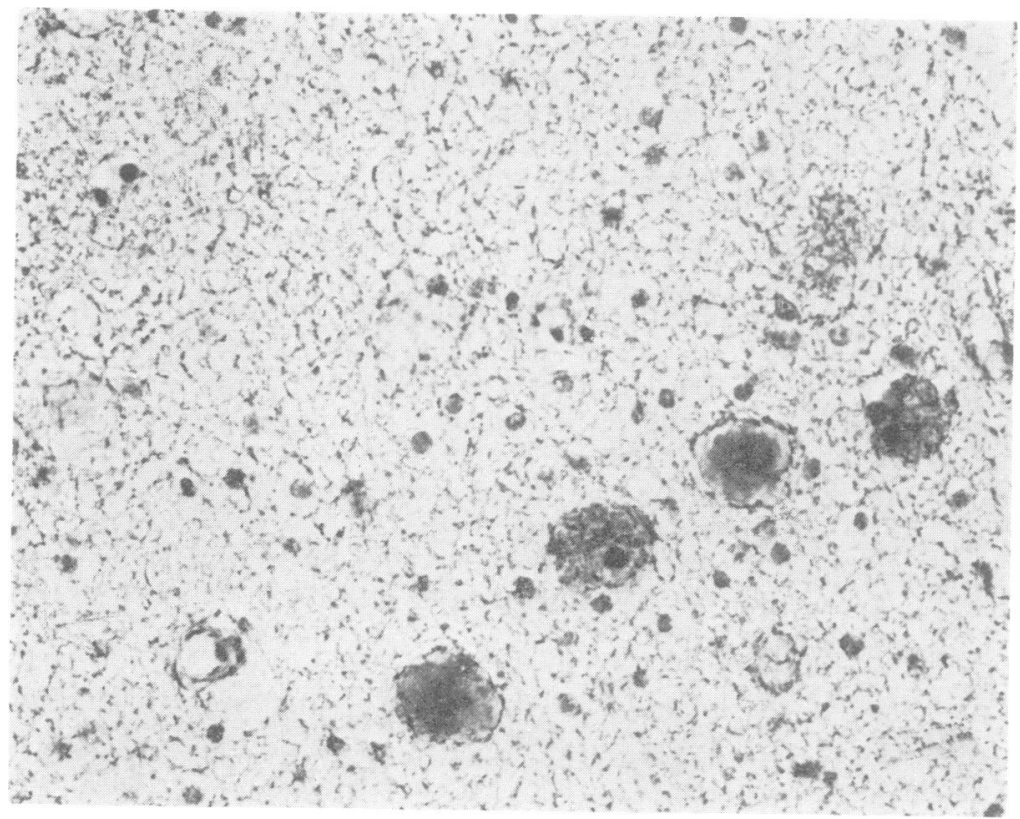

Fig. 6 Mucocytes in deep white matter. PAS $\times 250$. Celloidin section.

plates (Merck) which were activated at $130^{\circ} \mathrm{C}$ for one hour before use. After application of the lipid extracts the plates were developed in hexane: diethyl ether: acetic acid $(80: 20: 1)$. Spots were visualised in iodine vapour.

\section{Results}

Liver The results of thin layer chromotography of lipid extracts from liver are illustrated in Fig. 9a. Two fractions are found in the patients with
Refsum's disease which are not found in the controls. These fractions migrate slightly in advance of the main triglyceride fractions, and are thought to represent triglycerides in which phytanic acid has been substituted for the normally occurring fatty acids. Some increase is also noted in the cholesterol ester fraction in the cases of Refsum's disease.

Kidney Thin layer chromotography of kidney extracts shows a marked increase in the amounts of cholesterol esters which are present (Fig. 9b).

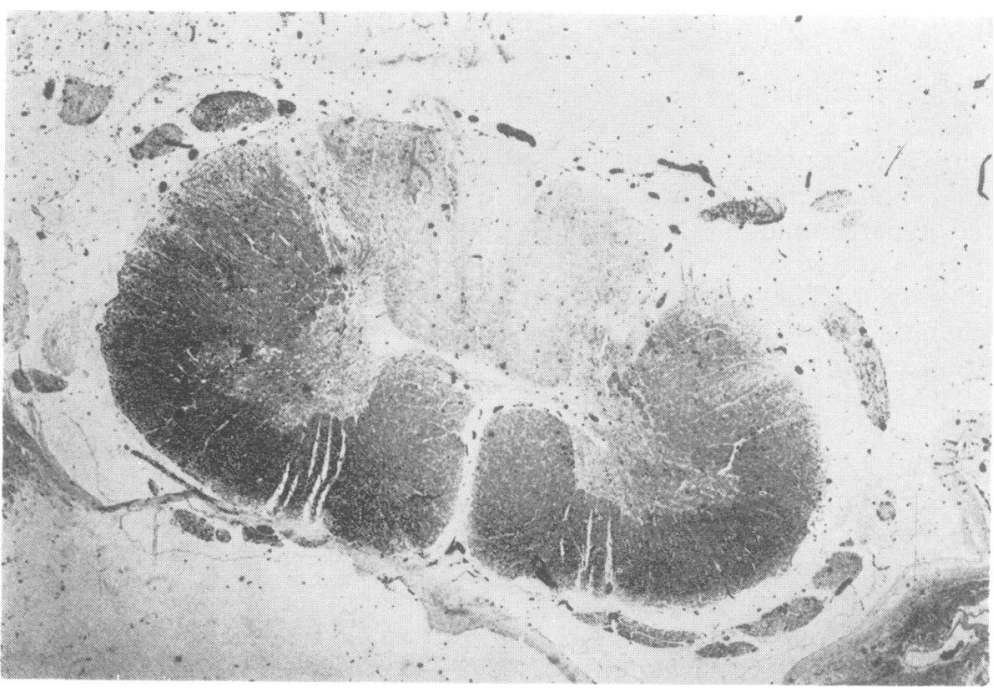

Fig. 7 Spinal cord (cervical). There is loss of myelin staining in the posterior columns. Woelcke. 


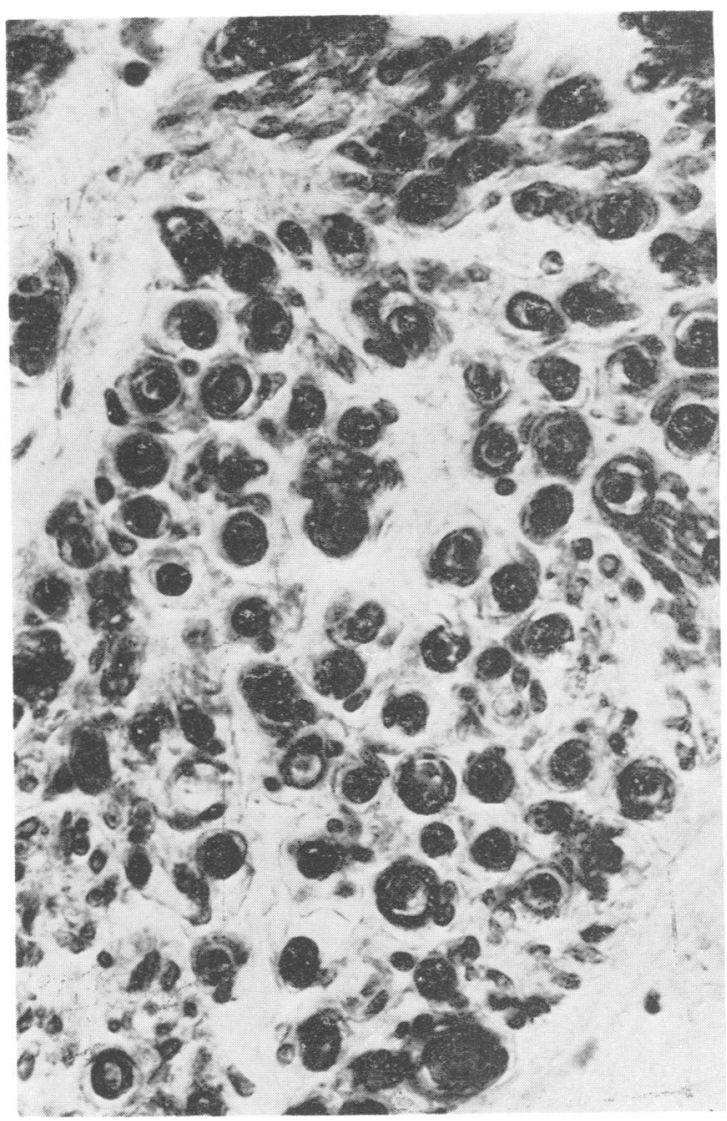

Fig. 8 Peripheral nerve showing variation in myelin staining around axis cylinders. Spielmeyer/fat $\times 400$.

The two phytanic acid-containing triglycerides are present in the kidneys of the patients with Refsum's disease.

Heart In the chromatographic analysis of lipid extracts of heart, (Fig. 9c) the two phytanic acidcontaining triglycerides were also found to be present.

Brain No abnormality of the brain lipids was observed on thin layer chromotography of brain lipid extracts.

\section{Discussion}

The condition of heredopathia atactica polyneuritiformis was first described by Refsum (1945, 1946a,b) although Thiébaut et al. (1939) described a case later shown to be the same condition (Thiébaut et al., 1961). Since the demonstration by Klenk and Kahlke (1963) of an abnormality in serum phytanic acid in a patient with Refsum's disease, extensive biochemical studies have been undertaken. The disease is a rarity, and to date only 73 cases have been published (Refsum, 1975) with necropsy reports in 20 of these. In Ireland nine cases (including the two reported in the present communication) have been recorded from three families, (Ashenhurst et al., 1958; Nevin et al., 1967; Quinlan and Martin, 1970). Most cases in the world literature have been of Scandinavian origin, and it may be significant that the family name of Skillen in the present cases is of Norse origin, and is found around Strangford Lough in Northern Ireland where most of the islands bear Norse names (Gibbie, personal communication, 1976).

The two patients described in this paper present many of the well recognised clinical features of Refsum's disease. Thus, both showed a severe polyneuropathy with typical retinitis pigmentosa, lens opacities and (in case 1) glaucoma and corneal dystrophy. Both patients were deaf, and case 2 had anosmia. Skeletal abnormality, a feature of this disease and also of other disorders of lipid metabolism (Spranger, 1969), was represented in the congenital shortening of the fourth metatarsal in case 1: case 2 had dry scaly skin. Case 1 experienced such severe total sensory deprivation that communication became impossible.

The effect of a diet low in phytanic acid on the course of this disease was first described by Eldjarn et al. (1966), and more recent reports have confirmed that some patients improve on this treatment (Quinlan and Martin, 1970; Millar personal communication, 1976). Attempts were made to introduce such a diet in case 2 but the patient could not tolerate the limitations imposed, and was unable to follow it for any length of time.

The first necropsy on the syndrome later described by Refsum was performed by Jansen in 1938 and recorded by Cammermeyer (1956) who himself has undertaken detailed pathological studies (1946, 1954, 1956, and 1957). Cammermeyer has summarised the essential anatomical abnormalities as those of interstitial hypertrophic polyneuropathy, degeneration of brainstem tracts with primary damage to myelin, atrophy of inferior olivary nuclei, and reactive changes in sympathetic ganglia. The suggestion that the disease is a lipidosis was originally his. Other pathological reports have also stressed the abnormalities in the central and peripheral nervous system but in most patients other organs are affected and abnormalities of the eye, ear, liver, kidney, heart, testes, and skin have been recorded by Cammermeyer (1975). In the present cases one of the striking pathological features was the 

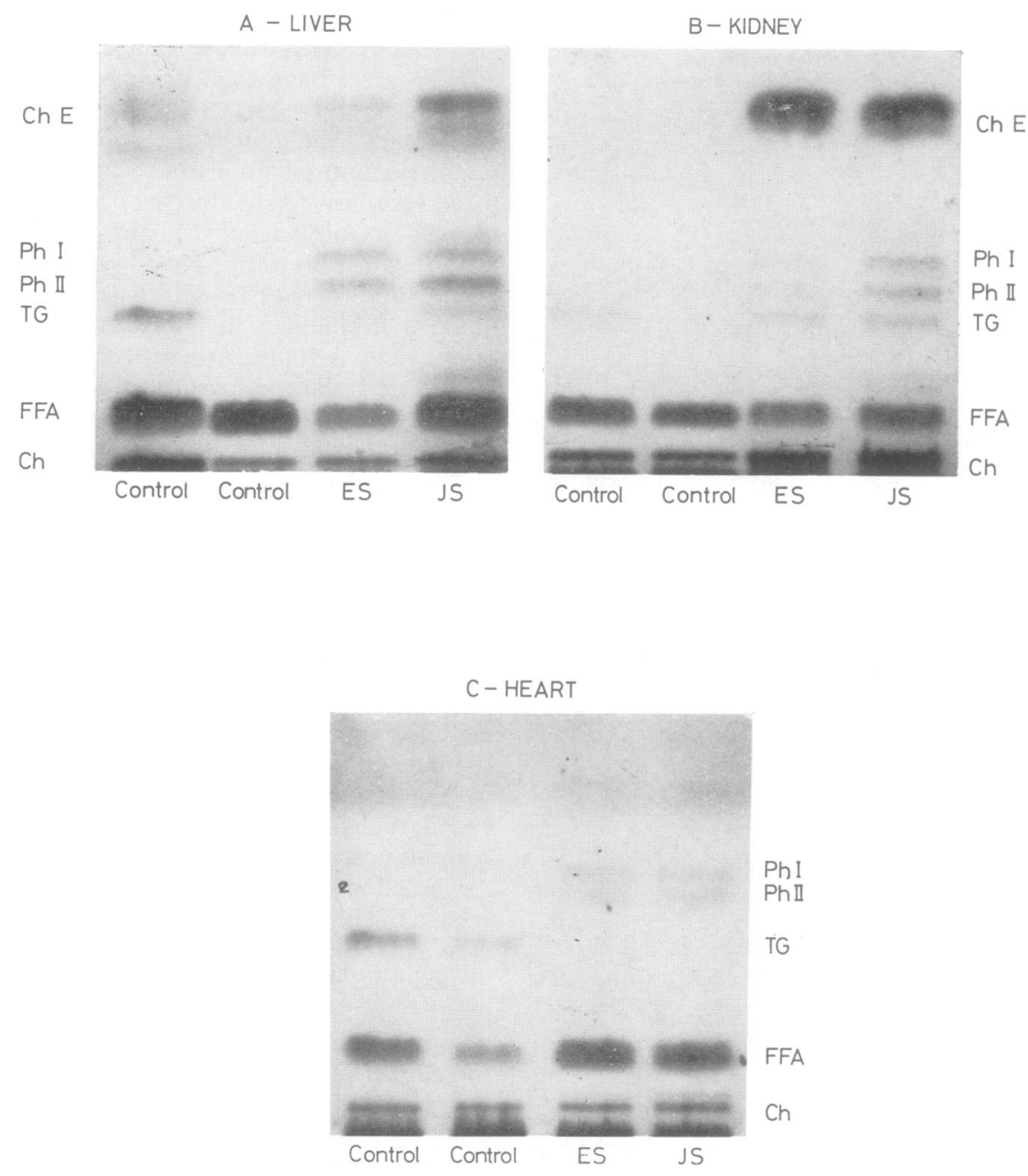

Fig. 9 Tissue lipid chromatograms in patients (JS case 1, and ES case 2) and controls. CLE-cholesterol esters, Ph I and II-triglycerides containing phytanic acid, TGtriglycerides, FFA-free fatty acids, Ch-cholesterol.

heavy deposition of neutral fat in renal tubular epithelium, liver epithelium and in myocardium: tissue analysis confirmed abnormal deposition of phytanic acid in these organs. The female sibling of the present cases previously reported also showed vacuolation of tubular epithelium (Nevin et al., 1967). Cammermeyer et al. in 1954 noted vacuolation of renal tubular epithelium, and since then this has been observed frequently, and abnormal levels of phytanic acid have been recorded in Refsum's disease in kidney, heart, and liver (Kahlke, 1964; Skrbic and Cumings, 1969). In none of the cases reported, however, has renal failure developed and the significance of an elevated blood urea in our case must be debated. Certainly in this patient there was severe renal lipidosis, and his abnormal phytanic acid metabolism may have been the prime factor in his renal failure. It must be conceded, however, that he had a mild degree of chronic pyelonephritis which may have been a contributory factor.

The three affected members of the present family illustrate the variability of the clinical picture and mode of death in Refsum's diseaseMMcA (case 2, Nevin et al., 1967) died of acute polyneuritis after her fourth pregnancy; of our cases, 1 (JS) developed renal failure and 2 (ES) died from chronic heart failure which, in the absence 
of significant ischaemic heart disease, is best explained by the fatty deposition in the myocardium.

The findings in the peripheral nervous system in the present cases are identical to those described by other authors though the findings in the central nervous system are less striking than in many other reports. In particular, fat was not observed in meninges or in the brain substance generally, although neutral fat could be demonstrated in the globus pallidus and choroid plexus. Inferior olivary atrophy was not seen, and there was little evidence of primary demyelination in the brain. The pallor of myelin staining in the posterior columns of the spinal cord was considered to be secondary to the peripheral neuropathy, and it is possible that the demyelination of optic and auditory nerves may have been, in part, secondary to end organ degeneration. In both cases the main changes in the brain were an increase in the number of oligodendrocytes and formation of mucocytes or metachromatic bodies as described by Smith (1949). Increase in the number of oligodendrocytes has been described by several authors and probably reflects the chronic damage to central myelin. Van Bogaert et al. (1967) described acute swelling of oligodendrocytes in their case but this common postmortem finding was not discussed, and was presumably considered nonspecific. The abnormality observed in the present cases was identical to that described by Smith (1949) who observed it in human brain and in horses with grass sickness. These mucocytes or metachromatic bodies, which contain mucopolysaccharide but not fat, are thought to differ from the so-called acutely swollen oligodendrocyte: mucocytes show marked ballooning with distinctive metachromasia and are commonly aggregated. The significance of such changes in oligodendrocytes is debated, and the possibility of artefact cannot be excluded. However, it seems worthwhile to emphasise the abnormality in the present metabolic disorder which by prolonged interference with oligodendrocyte metabolism might predispose to such a change.

The use of silica gel thin layer chromatography in the diagnosis of Refsum's disease was first described by Karlsson et al. (1967). In patients with Refsum's disease, two additional triglyceride fractions are present. These are thought to represent triglyceride molecules in which either one or two molecules of phytanic acid are present. The technique is inexpensive and simple to use and is a convenient method for the biochemical diagnosis of Refsum's disease in laboratories without access to more sophisticated analytical methods such as gas chromatography. In the present cases phytanic acid-containing triglycerides and increased amounts of cholesterol esters were demonstrated in heart, liver, and kidney but not in brain. The apparent total absence of phytanic acid from cerebral tissue in the present cases may be a reflection of the lesser sensitivity of thin layer chromatography as compared with gas chromatography since other workers have demonstrated phytanic acid in brain (MacBrinn and O'Brien, 1968).

Although the significant biochemical defect in Refsum's disease has been demonstrated, many of the clinical and pathological features have not been explained-for example, the fluctuating nature of the condition is not understood, and the pathogenesis of the abnormally high CSF protein is also uncertain. The pathological significance of the abnormal metabolism in brain, peripheral nerve, eye, ear, heart, skin and bone is apparent but the link between the molecular abnormality, possibly at a mitochondrial level, and the subsequent cellular changes is still unknown.

\section{References}

Ashenhurst, E. M., Millar, J. H. D., and Milliken, T. G. (1958). Refsum's syndrome affecting a brother and two sisters. British Medical Journal, 2, 415-417.

Bogaert, L. van., Mechelen, P. van., Martin, J. J., and Guazzi, G. C. (1967). Sur la neuropathologie de la maladie de Refsum-Thiébaut. (Protocole de l'observation de Richterich Kahlke, van Mechelen et Rossi, 1963). Revue Neurologique, Paris, 116, 229 240.

Cammermeyer, J. (1946). Om de anatomiske funn i to tilfelle av dr. S. Refsum's materiale av 'et tidligere ikke beskrevet (?) familiaert syndrom'. Nordisk Medicin, 29, 617.

Cammermeyer, J. (1956). Neuropathological changes in hereditary neuropathies. Manifestation of the syndrome heredopathia atactica polyneuritiformis in the presence of interstitial hypertrophic polyneuropathy. Journal of Neuropathology and Experimental Neurology, 15, 340-361.

Cammermeyer, J. (1975). Refsum's disease, neuropathological aspects. Handbook of Clinical Neurology, Vol. 21 System Disorders and Atrophies. Part 1. Chapter 11, pp. 231-261. North-Holland Publishing Company: Amsterdam.

Cammermeyer, J., Haymaker, W., and Refsum, S. (1954). Heredopathia atactica polyneuritiformis: the neuropathologic changes in three adults and one child. American Journal of Pathology, 30, 643-644.

Eldjarn, L., Try, K., Stokke, O., Munthe-Kass, A. W., Refsum. S., Steinberg. D., Avigan, J., and Mize, C. (1966). Dietary effects on serum-phytanic-acid levels and on clinical manifestations in heredopathia atactica polyneuritiformis. Lancet, 1, 691-693.

Folch, J., Lees, M., and Sloane Stanley, G. H. (1957). A simple method for the isolation and purification of total lipides from animal tissues. Journal of Biological Chemistry. 226, 497-509. 
Herndon, H. J., Steinberg, D., and Uhlendorf, B. W. (1969). Refsum's Disease: defective oxidation of phytanic acid in tissue cultures derived from homozygotes and heterozygotes. New England Journal of Medicine, 281, 1034-1038.

Kahlke, W. (1964). Refsum-Syndrome. Lipoidchemische Untersuchungen bei 9 Fallen. Klinische Wochenschrift, 42, 1011-1016.

Karlsson, K. A., Norrby, A., and Samuelsson, B. (1967). Use of thin-layer chromatography for the preliminary diagnosis of Refsum's disease (Heredopathia atactica polyneuritiformis). Biochimica et Biophysica Acta, 144, 162-164.

Klenk, E., and Kahlke, W. (1963). Uber das Vorkommen der 3,7,11,15- Tetramethyl-hexadecansaure (Phytänsaure) in den Cholesterinestern und anderen Lipoidfraktionen der Orange bei einem Krankheitsfall unbekannter Genese (Verdacht auf Heredopathia atactica polyneuritiformis [Refsum-Syndrom]). Hoppe Seylers Zeitschrift für Physiologische Chemie, 333, 133-139.

MacBrinn, M. C., and O'Brien, J. S. (1968). Lipid composition of the nervous system in Refsum's disease. Journal of Lipid Research, 9, 552-561.

Nevin, N. C., Cumings, J. N., and McKeown, F. (1967). Refsum's syndrome. Heredopathia atactica polyneuritiformis. Brain, 90, 419-428.

Quinlan, C. D., and Martin, E. A. (1970). Refsum's syndrome: report of three cases. Journal of Neurology, Neurosurgery, and Psychiatry, 33, 817-823.

Refsum, S. (1945). Heredoataxia hemeralopica polyneuritiformis-et tidligere ikke beskrevet familiaert syndrom? Nordisk Medicin, 28, 2682-2686.

Refsum, S. (1946a). Et tidligere ikke beskrevet (?) familiaert syndrom-'heredo-ataxia hemeralopica polyneuritiformis. Nordisk Medicin, 29, 617-618.

Refsum, S. (1946b). Heredopathia atactica polyneuritiformis: a familial syndrome not hitherto described. A contribution to the clinical study of the hereditary diseases of the nervous system. Acta Psychiatrica Scandinavica, Supplement 38, 1-303.

Refsum, S. (1975). Heredopathia atactica polyneuritiformis. Phytanic acid storage disease (Refsum's disease). Handbook of Clinical Neurology Vol 21. System Disorders and Atrophies. Part 1. Chapter 10, pp. 181-229. North Holland Publishing Company: Amsterdam.

Skrbic, T. R., and Cumings, J. N. (1969). Phytanic acid in tissue lipids in Refsum's disease. Clinica Chimica Acta, 23, 17-21.

Smith, M. (1949). Metachromatic bodies in the brain. Journal of Neurology, Neurosurgery, and Psychiatry, 12, $100-110$.

Spranger, J. (1969). Mucopolysaccharidoses and mucolipidoses. Annales de Radiologie, 12, 981-991.

Thiébaut, F., Lemoyne, J., and Guillaumat, L. (1939). Deux syndromes oto-neuro-oculistiques d'origine congénitale. Leurs rapports avec les phacomatoses de van der Hoeve et autres dysplasies neuro-ectodermiques. Revue Neurologique, Paris, 72, 71-75.

Thiébaut, F., Lemoyne, J., and Guillaumat, L. (1961). Maladie de Refsum. Revue Neurologique, Paris, 104, 152-154. 